\title{
两种自动基流分割方法在干旱半干旱 地区的对比研究
}

\author{
李 瑞 $1,2,3$, 张士锋 $1,2^{*}$ \\ (1. 中国科学院地理科学与资源研究所, 北京 $100101 ; 2$. 中国科学院陆地水循环及地表过程重点实验室, \\ 北京 $100101 ; 3$. 中国科学院大学, 北京 100049)
}

\begin{abstract}
摘 要: 基流是河川径流的重要组成部分。在干旱半干旱地区, 基流对于维持水源的稳定性及持续性、确定河流生 态需水等方面具有重要作用。因此, 基流分割结果的准确性至关重要。本文以黄河流域上游小流域为研究区, 分 别使用滑动最小值法和数字滤波法对典型年进行基流分割, 然后用数字滤波法对 1980-2014年日均径流进行基流 分割,并分析基流的变化趋势。研究表明,数字滤波法在干旱半干旱地区具有较好的应用效果, 滑动最小值法分割 的基流结果偏小; 在特定研究区的参数难以确定时, 应结合两种方法的优点确定最佳的基流分割方案。研究区 1980-2014年的平均基流指数为 0.69 , 高于全国平均值 0.26 、西北诸河区的 0.57 及黄河区的 0.43 ; 趋势分析显示, 研 究区的年径流、基流、BFI的增长幅度分别为 $0.086\left(\mathrm{~m}^{3} / \mathrm{s}\right) / 10 \mathrm{a} 、 0.169\left(\mathrm{~m}^{3} / \mathrm{s}\right) / 10 \mathrm{a} 、 0.038 / 10 \mathrm{a} 。 \mathrm{MK}$ 趋势检验结果显示, 年径流未通过 $10 \%$ 的显著性检验, 增长趋势不明显; 基流和 BFI 分别通过了 $2.5 \%$ 和 $1 \%$ 的显著性检验, 增长趋势 显著。
\end{abstract}

关 键 词:干旱半干旱地区; 自动基流分割;滑动最小值法;数字滤波法;基流指数

\section{1 引言}

基流是河川径流的重要组成部分。研究显示, 黄河基流量约占河川径流量的 44\%, 唐乃亥以上黄 河源区的多年平均基流量与河川径流量的比值更 高达 65.2\%(陈利群, 刘昌明, 郝芳华等, 2006; 王雁 林等, 2008)。基流在水安全、粮食安全、非点源污 染评价, 水资源评价和调查, 水资源配置、工农业供 水和降雨一径流关系模拟中有着广泛的应用(陈利 群, 刘昌明, 李发东, 2006)。此外, 在干旱半干旱地 区,基流对于维持水源的稳定性及持续性、确定河 流生态需水等方面具有重要作用。

基流分割方法很多。传统的基流分割方法主 要为图解法,包括斜线分割法、下包线分割法、近似 的平割法等, 其繁琐性和人为主观性使得分割效率
和精度难以保证。近年来,采用数学方法分割流量 过程线的自动分割技术得到了快速发展, 主要包括 滑动最小值法(Aksoy et al, 2009)、数字滤波法(Nathan et al, 1990)、HYSEP 法(Sloto et al, 1996)、PART 法(Rutledge, 1998)等。其中应用最广的是滑动最小 值法和数字滤波法。滑动最小值法(Smoothed Minima, SM)最早由英国水文研究所(UKIH)在 1980 年 提出, 其核心是通过连接流量过程线上的一系列拐 点从而得到基流过程,该方法所需资料较少, 原理 清晰, 操作简便, 已在很多国家和地区得到应用 (Wahl et al, 1995; 黄国如, 2007; 张文娜等, 2015)。 数字滤波法来源于信号分析, 由 Nathan(1990)于 1990 年首次应用于水文研究中, 其核心是通过滤波 手段对不同频率的径流成分进行信号分离,达到基 流分割的目的。该方法参数少、精度高、且具有较

收稿日期: 2016-07; 修订日期:2016-12。

基金项目: 中国科学院重点部署项目(KFZD-SW-301); 国家自然科学基金项目(41171032)[Foundation: Key Research Program of the Chinese Academy of Sciences, No.KFZD-SW-301; National Natural Science Foundation of China, No.41171032]。

作者简介:李瑞(1990-), 男,河南济源人,硕士研究生,研究方向为水文水资源, E-mail: lirui6553@163.com。

通讯作者: 张士锋(1965-), 男, 湖北荆州人, 副研究员, 研究方向为水文水资源,E-mail: zhangsf@igsnrr.ac.cn。 2017. Comparative study on two automatic baseflow separation methods in the arid and semi-arid regions[J]. Progress in Geography, 36 (7): 864-872.]. DOI: 10.18306/dlkxjz.2017.07.008 
好的客观性和可重复性,也是一种模仿人工分割流 量过程线的重要方法, 已经在实践中得到了大量的 验证(豆林等, 2010)。Arnold 在美国西部和东部选 取 6 个代表流域对该方法进行验证,结果表明该法 能够取代手工分割且能客观准确地再现基流(Arnold et al, 1995)。近年来, 国内学者也广泛使用数 字滤波法在黑河上游、三峡库区及黄土高原等区域 开展了基流分割的相关研究和探讨(崔玉洁等, 2011; 雷泳南等, 2011; 张华等, 2011)。

干旱半干旱地区约占全球陆地面积的 30\%, 中 国国土面积的 $42 \%$ 位于干旱半干旱地区。这里地 形变化复杂, 降水稀少且时空差异大, 小流域径流 量偏小且年内、年际分布不均, 基流分割工作面临 较多问题, 其分割结果的准确性直接影响流域水资 源开发保护与优化配置、水利工程设计与施工、农 田灌溉等措施的顺利实施。因而, 针对干旱半干旱 地区进行自动基流分割, 并准确地反映该区域河川 基流年际状况的研究迫在眉睫。然而, 滑动最小值 法和数字滤波法虽然简便易用, 但在实际应用中滑 动最小值法分割基流结果偏小, 数字滤波法在单独 使用时参数难以确定。因此, 开展滑动最小值法和 数字滤波法在干旱半干旱地区的对比研究, 不仅有 助于准确探究该地区的基流变化及特征, 支撑当地 水资源合理开发和利用, 而且对于发展和完善基流 分割理论也具有重要的实践意义。

\section{2 数据和方法}

\section{1 研究区域概况}

本文选取位于西北干旱半干旱地区的药水河 流域为研究区。药水河属黄河水系, 为湟水河右岸 一级支流, 发源于青海省东部湟源县境内。全流域 属高原山区, 处于黄土高原与青藏高原的过渡带, 属祁连山地槽禇皱系西宁断陷盆地。流域由河谷 阶地、丘陵、中山和高山组成, 沿河两岸地形有明显 禇皱, 河道两岸几乎形成对峙的平行山脉, 相对高 度大多在 $500 \mathrm{~m}$ 左右。地势由北、西、南向东倾斜。 流域内植被情况较好, 其中左岸较右岸好, 阴坡较 阳坡好。土壤垂直地带分布, 土壤类型多为壤土 土质。

流域形状呈扇形, 地理位置介于东经 $101^{\circ} 00^{\prime} \sim$ $102^{\circ} 21^{\prime}$ 、北纬 $36^{\circ} 09^{\prime} \sim 36^{\circ} 41^{\prime}$ 之间(图 1), 流域平均宽 度 $12.3 \mathrm{~km}$, 河源海拔 $4302 \mathrm{~m}$, 河口海拔 $2621 \mathrm{~m}$, 落

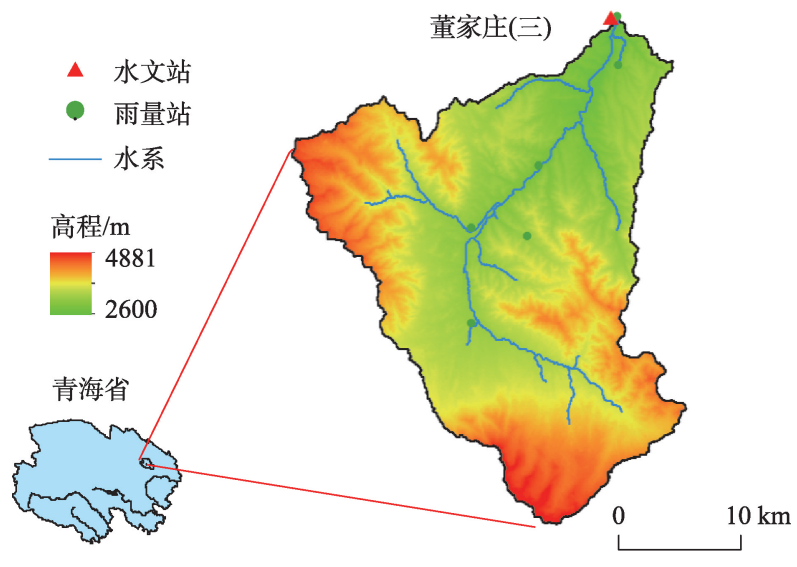

图 1 研究区位置及水系分布

Fig.1 Location and distribution of water system of the study area

差 $1681 \mathrm{~m}$, 干流河长 $52.2 \mathrm{~km}$, 河道平均比降 $32 \%$, 属山溪性河流, 常年流水。年降水量 400 500 mm, 年蒸发量 $737.9 \mathrm{~mm}$; 年径流总量为 0.90 亿 $\mathrm{m}^{3}$ 。流 域内广泛分布着松散岩类孔隙水、碳酸盐岩类裂隙 溶洞水及基岩裂隙水，下垫面透水性良好。流域的 产流兼具蓄满产流机制和超渗产流机制。径流以 降水补给为主, 径流量的年内变化与降水量的变化 趋势基本一致, 且年内分配不均。流量在 1-2 月较 为平稳, 分别为 $0.95 \mathrm{~m}^{3} / \mathrm{s}$ 和 $0.96 \mathrm{~m}^{3} / \mathrm{s} ; 3-4$ 月流量持 续上涨, 且涨幅较大; 5-10月为丰水期, 主要通过降 水补给, 流量维持在 $4.19 \mathrm{~m}^{3} / \mathrm{s}$ 左右; 进人 11 月, 流量 逐渐下降,一直持续到 12 月, 流量降至 $1.29 \mathrm{~m}^{3} / \mathrm{s}$ 。 流域内有 5 个雨量站, 出口设董家庄(三)水文站,集 水面积 $636 \mathrm{~km}^{2}$ 。

本文的数据基础为药水河流域出口董家庄(三) 站 1980-2014 年的日均流量数据, 均来源于青海省 水文水资源勘测局。

\section{2 研究方法}

本文使用的两种自动基流分割方法分别为滑 动最小值法和数字滤波法。此外, 为定量比较两种 方法的分割结果, 引人基流指数 BFI (Baseflow Index)。基流指数指一定流量序列中基流量在总径流 中的占比, 反映出河流水源的补给特性(雷泳南等, 2013)。即:

$$
B F I=\frac{\int_{t_{1}}^{t_{2}} b_{t} \mathrm{~d} t}{\int_{t_{1}}^{t_{2}} Q_{t} \mathrm{~d} t}
$$

式中: $b_{t}$ 为基流, $Q_{t}$ 为实测总径流。

\subsection{1 滑动最小值法}

滑动最小值法先将整个实测日均流量序列 
$\left(Q_{1}, Q_{2}, Q_{3}, \cdots, Q_{n}\right)$ 划分成若干单元( $5 d$ 为一个 单元), 且单元之间互不重叠, 然后提取各单元中的 最小值得到新的流量序列 $\left(q_{1}, q_{2}, q_{3}, \cdots, q_{n}\right)$, 之后将 该流量序列中相邻的 3 个流量值归为 1 组, 即为 $\left(q_{1}\right.$, $\left.q_{2}, q_{3}\right),\left(q_{2}, q_{3}, q_{4}\right), \cdots \cdots,\left(q_{t-1}, q_{t}, q_{t+1}\right)$ 。若 $q_{t}$ 满足 $k q_{t} \leqslant\left(q_{t-1}, q_{t+1}\right)$, 则确定其为拐点, 连接基流过程 线上的所有拐点, 并进行线性内插。若内插值大于 实测流量值, 则取对应的流量值作为该时刻的基流 值，且同时刻的地表径流值也必须满足非负条件。 其中乘法因子 $k$ 并没有实际的物理意义。很多研究 结果表明,当 $k$ 取 0.9 时, 可以得到较好的基流分割 结果(Aksoy et al, 2009; 董晓华等, 2010)。

\subsection{2 数字滤波法}

数字滤波法的原理是用高频信号模拟地表径 流, 低频信号模拟基流。将日径流资料作为地表径 流和基流的叠加, 利用信号处理技术将低频信号从 高频信号中分离, 从而从日径流中划分出基流。

滤波方程为:

$$
q_{t}=\beta q_{t-1}+[(1+\beta) / 2]\left(Q_{t}-Q_{t-1}\right)
$$

基流 $b_{t}$ 为:

$$
b_{t}=Q_{t}-q_{t}
$$

式中: $q_{t} 、 q_{t-1}$ 分别为 $t 、 t-1$ 时刻分割得到的地表径流; $Q_{t} 、 Q_{t-1}$ 分别为 $t 、 t-1$ 时刻的实测总径流; $\beta$ 为影响基 流衰减程度的滤波参数。相关研究表明, 要提高数 据的计算精度, 可对其进行一定次数地反复过滤 (Nathan et al, 1990)。

滤波按照如下规律进行: 第一道滤波以实测总 径流的第二个记录数为起点, 依照式(2)依次向后做 正向运算; 第二道滤波为逆向运算,计算起点为第 一道滤波分割得到的基流流量的倒数第二个数据， 第三道滤波为在第二道滤波计算结果上的正向运 算。根据地表径流与基流的物理性质, 即 $b_{t}>0$, $q_{t}>0$, 且 $Q_{t} \geqslant b_{t}, Q_{t} \geqslant q_{t}$ 。在运算过程中, 若 $b_{t}<0$, 则令 $b_{t}=0, q_{t}=Q_{t}$; 若 $b_{t}>Q_{t}$, 则令 $b_{t}=Q_{t}$; 若 $q_{t}<0$, 则赋值 $q_{t}=0, b_{t}=Q_{t}$ 。

本文以黄河上游药水河流域 1980-2014年日均 流量为基础数据, 分别用滑动最小值法和数字滤波 法对其中典型年的年径流过程进行基流分割, 确定 数字滤波法中适用于研究区的 $\beta$ 值和滤波次数; 然 后通过数字滤波法对研究区 1980-2014年的流量过 程进行基流分割,并分析 35 年来基流量的变化趋 势。选取最近的 4 年作为典型年, 其中包含了丰水
年 $(2012$ 年)、平水年 (2011 年、2014 年) 和枯水年 (2013 年)。

\section{3 结果与分析}

\section{1 滑动最小值法基流分割结果}

运用滑动最小值法对研究区典型年的流量过 程进行基流分割,所得结果见表 1 。可以看出,典型 年 $(2011 、 2012 、 2013 、 2014$ 年) 的年均径流分别为 $2.86 、 3.56 、 2.87 、 3.0 \mathrm{~m}^{3} / \mathrm{s}$, 滑动最小值法分割的平均 基流流量分别为 $2.22 、 2.83 、 2.37 、 2.19 \mathrm{~m}^{3} / \mathrm{s}$, 基流指 数 $B F I$ 分别为 $0.77 、 0.79 、 0.83$ 和 0.73 , 平均值为 0.78 。典型年基流的最大、最小值分别为 4.80 、 $1.06,6.63 、 0.85,4.80 、 1.24$ 和 $3.54 、 0.97 \mathrm{~m}^{3} / \mathrm{s}$ 。由表 1 可见,2012 年的基流变化最不稳定,且丰水年的最 大基流流量并非大于枯水年的最大基流流量。

从图 2 可以看出, 2012、2014年的日均最大径

表 1 滑动最小值法 2011-2014 年基流分割结果

Tab.1 Results of baseflow separation of smoothed minima, 2011 - 2014

\begin{tabular}{cccccc}
\hline 年份 & $\begin{array}{c}\text { 年均径流/ } \\
\left(\mathrm{m}^{3} / \mathrm{s}\right)\end{array}$ & $\begin{array}{c}\text { 平均基流/ } \\
\left(\mathrm{m}^{3} / \mathrm{s}\right)\end{array}$ & $\begin{array}{c}\text { 最大基流/ } \\
\left(\mathrm{m}^{3} / \mathrm{s}\right)\end{array}$ & $\begin{array}{c}\text { 最小基流/ } \\
\left(\mathrm{m}^{3} / \mathrm{s}\right)\end{array}$ & $B F I$ \\
\hline 2011 & 2.86 & 2.22 & 4.80 & 1.06 & 0.77 \\
2012 & 3.56 & 2.83 & 6.63 & 0.85 & 0.79 \\
2013 & 2.87 & 2.37 & 4.80 & 1.24 & 0.83 \\
2014 & 3.00 & 2.19 & 3.54 & 0.97 & 0.73 \\
\hline
\end{tabular}
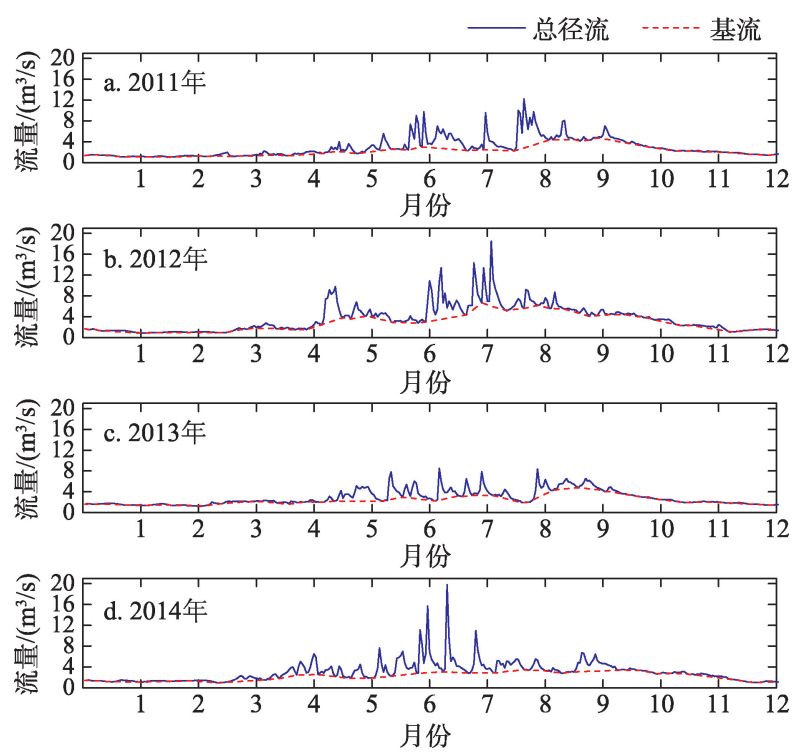

图 2 2011-2014年滑动最小值法基流分割结果

Fig.2 Results of baseflow separation of smoothed minima, 2011 - 2014 
流量分别达到了 $18.5 \mathrm{~m}^{3} / \mathrm{s}$ 和 $19.8 \mathrm{~m}^{3} / \mathrm{s}$, 较 2011 、 2013 年的径流量大。滑动最小值法分割出的基流 变化趋势与总径流的变化趋势一致: 1-3月、11-12 月总径流和基流非常接近, 且过程都比较稳定; 在 丰水期总径流起伏变化较为剧烈, 基流也呈现相同 的变化趋势; 丰水期后, 基流和总径流都开始下降 并最终趋于稳定。

\section{2 数字滤波法基流分割结果}

以 2012 年基流分割为例: $\beta$ 分别取 $0.80 、 0.90$ 、 $0.925 、 0.95 、 0.975$, 滤波次数分别为 1 次、 2 次、 3 次, 其中 1 次滤波指对流量过程进行 1 次正向过滤, 2 次 滤波指“正一反”2次过滤, 3 次滤波指“正一反一正” 3 次反复过滤。数字滤波法对基流的过滤次数超过 3 次后, 高频信号并未进一步衰减。因此, 本文在使 用滤波法分割基流时最多进行 3 次滤波, 所得基流 分割结果见图 3。1-3 月, 当流量过程起伏变化不大 时, 不同的 $\beta$ 取值和滤波次数分割的基流过程无显 著差异。在丰水期流量较大且变化起伏较明显时, $\beta$ 值和滤波次数对基流的分割结果影响较大。

从表 2 可以看出, $\beta$ 取值 0.80 时, 3 次滤波得到 的基流指数 $B F I$ 分别为 $0.89 、 0.83 、 0.79$, 分割的最大 基流流量逐次减小, 分别为 $9.45 、 7.49 、 6.81 \mathrm{~m}^{3} / \mathrm{s}$ 。 同理, $\beta$ 取其他值时,滤波次数增加会导致分割出 的基流减小。当 $\beta$ 依次取值 $0.80 、 0.90 、 0.925 、 0.95$ 、 0.975 时,第 3 次滤波得到的 $B F I$ 分别为 $0.79 、 0.72$ 、 $0.69 、 0.64 、 0.53$, 分割基流的平均值分别为 2.81 、 $2.58 、 2.68 、 2.30 、 1.89 \mathrm{~m}^{3} / \mathrm{s}$, 最大值分别为 $6.81 、 5.73 、$ $6.23 、 5.07 、 4.02 \mathrm{~m}^{3} / \mathrm{s}$; 即当滤波次数一定时, 随着 $\beta$ 值增大, 基流逐渐变小, 基流量所占比例也逐渐变 小。由此可见, 在使用数字滤波法进行流量过程的 基流分割时,增大 $\beta$ 值或增加滤波次数都可使高频 信号获得衰减, 基流过程线趋于平滑, 基流量变 小。从基流量变化的角度分析, $\beta$ 依次取不同数 值, 基流量分别衰减了 $10.6 \% 、 14.5 \% 、 16.0 \%$ 、
$18.1 \%, 22.8 \%, 6.4 \%, 8.3 \%, 9.2 \%, 11.0 \% 、 14.5 \%$, $4.6 \% 、 6.0 \% 、 6.9 \% 、 8.6 \% 、 10.9 \%$ 。由此可见，当 $\beta$ 值 一定时, 随着滤波次数增加, 基流量的衰减率越来 越小; 当滤波次数一定时, $\beta$ 值越大,基流量的衰减 率越大。

\section{3 两种方法的对比}

表 3 为研究区典型年数字滤波法和滑动最小值 法计算出的 BFI值的对比。表 3 再次验证了在数字 滤波法中,增大 $\beta$ 值或增加滤波次数,基流指数都 会逐渐减小, 有时甚至出现“异参同效”(芮孝芳等, 2007) 问题。 $\beta$ 取 0.80 并经过“正一反一正” 3 次滤 波,与 $\beta$ 取 0.90 并经过“正一反” 2 次滤波得到的基 流指数都与滑动最小值法的结果接近。但由于滑 动最小值法主要是按照在划分时段内的最小值的 连线来进行基流分割,故一般得到的基流量都会偏 小。从这个角度分析, $\beta$ 取 0.80 并经过“正一反一
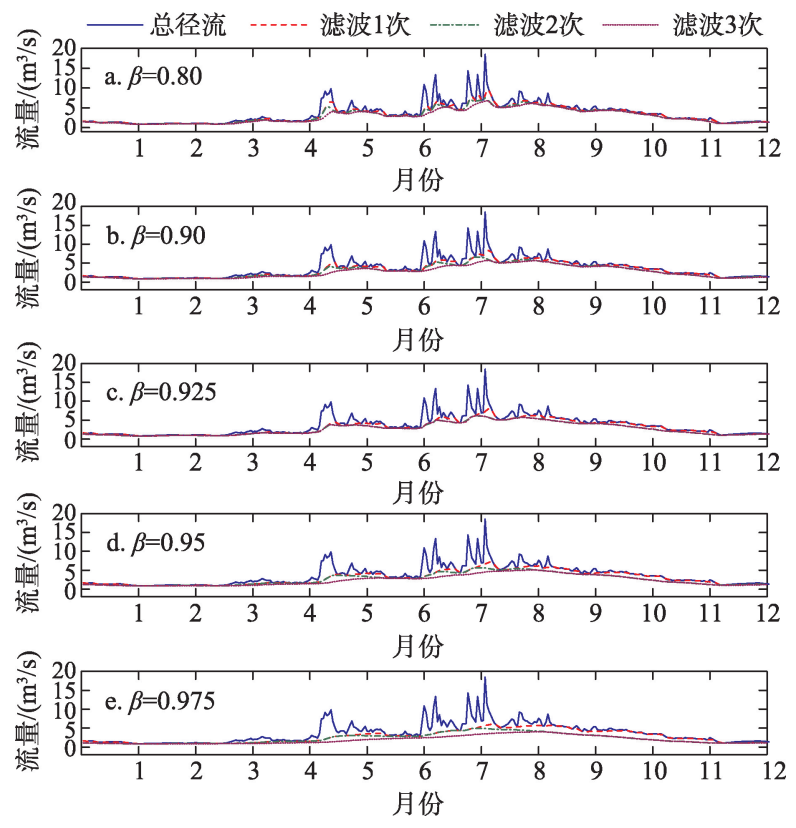

图 3 数字滤波法 $\beta$ 取不同值时的 3 次滤波结果

Fig.3 Results of three third time rounds filtration when $\beta$ equals totakes different values of in digital filtering

表 2 数字滤波法 2012 年基流分割结果

Tab.2 Results of baseflow separation of digital filtering, 2012

\begin{tabular}{|c|c|c|c|c|c|c|c|c|c|c|c|c|c|c|c|}
\hline \multirow{2}{*}{ 滤波次数 } & \multicolumn{3}{|c|}{$\beta=0.80$} & \multicolumn{3}{|c|}{$\beta=0.90$} & \multicolumn{3}{|c|}{$\beta=0.925$} & \multicolumn{3}{|c|}{$\beta=0.95$} & \multicolumn{3}{|c|}{$\beta=0.975$} \\
\hline & 1 & 2 & 3 & 1 & 2 & 3 & 1 & 2 & 3 & 1 & 2 & 3 & 1 & 2 & 3 \\
\hline 最大基流/( $\left.\mathrm{m}^{3} / \mathrm{s}\right)$ & 9.45 & 7.49 & 6.81 & 8.45 & 6.60 & 5.73 & 8.16 & 6.23 & 6.23 & 7.26 & 5.69 & 5.07 & 6.08 & 4.91 & 4.02 \\
\hline 最小基流/( $\left.\mathrm{m}^{3} / \mathrm{s}\right)$ & 0.85 & 0.85 & 0.85 & 0.85 & 0.85 & 0.85 & 0.85 & 0.85 & 0.85 & 0.85 & 0.85 & 0.85 & 0.85 & 0.85 & 0.85 \\
\hline 平均基流 $/\left(\mathrm{m}^{3} / \mathrm{s}\right)$ & 3.16 & 2.95 & 2.81 & 3.03 & 2.76 & 2.58 & 2.98 & 2.67 & 2.68 & 2.89 & 2.54 & 2.30 & 2.71 & 2.24 & 1.89 \\
\hline$B F I$ & 0.89 & 0.83 & 0.79 & 0.85 & 0.77 & 0.72 & 0.84 & 0.75 & 0.69 & 0.81 & 0.71 & 0.64 & 0.76 & 0.63 & 0.53 \\
\hline
\end{tabular}


表 3 数字滤波法和滑动最小值法 BFI 比较

Tab.3 Comparison of BFI between digital filtering and smoothed minima

\begin{tabular}{|c|c|c|c|c|c|c|c|c|c|c|c|c|c|c|c|c|}
\hline & \multicolumn{15}{|c|}{ 数字滤波法 } & \multirow{3}{*}{$\begin{array}{l}\text { 滑动最 } \\
\text { 小值法 }\end{array}$} \\
\hline & \multicolumn{3}{|c|}{$\beta=0.80$} & \multicolumn{3}{|c|}{$\beta=0.90$} & \multicolumn{3}{|c|}{$\beta=0.925$} & \multicolumn{3}{|c|}{$\beta=0.95$} & \multicolumn{3}{|c|}{$\beta=0.975$} & \\
\hline & 1 & 2 & 3 & 1 & 2 & 3 & 1 & 2 & 3 & 1 & 2 & 3 & 1 & 2 & 3 & \\
\hline 2011年 & 0.89 & 0.83 & 0.80 & 0.86 & 0.78 & 0.74 & 0.84 & 0.76 & 0.71 & 0.82 & 0.73 & 0.67 & 0.77 & 0.66 & 0.59 & 0.77 \\
\hline 2012年 & 0.89 & 0.83 & 0.79 & 0.85 & 0.77 & 0.72 & 0.84 & 0.75 & 0.69 & 0.81 & 0.71 & 0.64 & 0.76 & 0.63 & 0.53 & 0.79 \\
\hline 2013 年 & 0.91 & 0.86 & 0.82 & 0.88 & 0.81 & 0.75 & 0.86 & 0.78 & 0.72 & 0.83 & 0.73 & 0.68 & 0.77 & 0.67 & 0.61 & 0.83 \\
\hline 2014年 & 0.86 & 0.80 & 0.76 & 0.83 & 0.75 & 0.70 & 0.81 & 0.72 & 0.68 & 0.78 & 0.69 & 0.64 & 0.74 & 0.63 & 0.57 & 0.73 \\
\hline
\end{tabular}

正” 3 次滤波要优于 $\beta$ 取 0.90 并经过 “正一反” 2 次 滤波得到的基流分割结果。

图 4 为 $\beta$ 取 0.80 并经过 “正一反一正” 3 次滤 波,与 $\beta$ 取 0.90 并 “正一反” 2 次滤波分割研究区典 型年汛期(6-9月)的基流过程对比图, 可以看出两 组参数下得到的基流过程线都较为平缓。 $\beta$ 取 0.80 并经过 3 次滤波比 $\beta$ 取 0.90 并经过 2 次滤波得 到的基流过程线的波峰更滞后于径流过程线的波 峰。由于研究区植被覆盖较好, 下垫面对基流的阻 尼效应更加明显。因此, $\beta$ 取 0.80 , 经过 “正一反一 正”3 次滤波分割的基流过程线更加符合实际基流 的平缓性与迟滞性的特点。为进一步比较数字滤 波法与滑动最小值法的基流分割特点, 令 $\beta$ 取 0.80 , 经过 “正一反一正” 3 次滤波的分割结果与滑 动最小值法的分割结果进行对比。从图 5 看出, 两
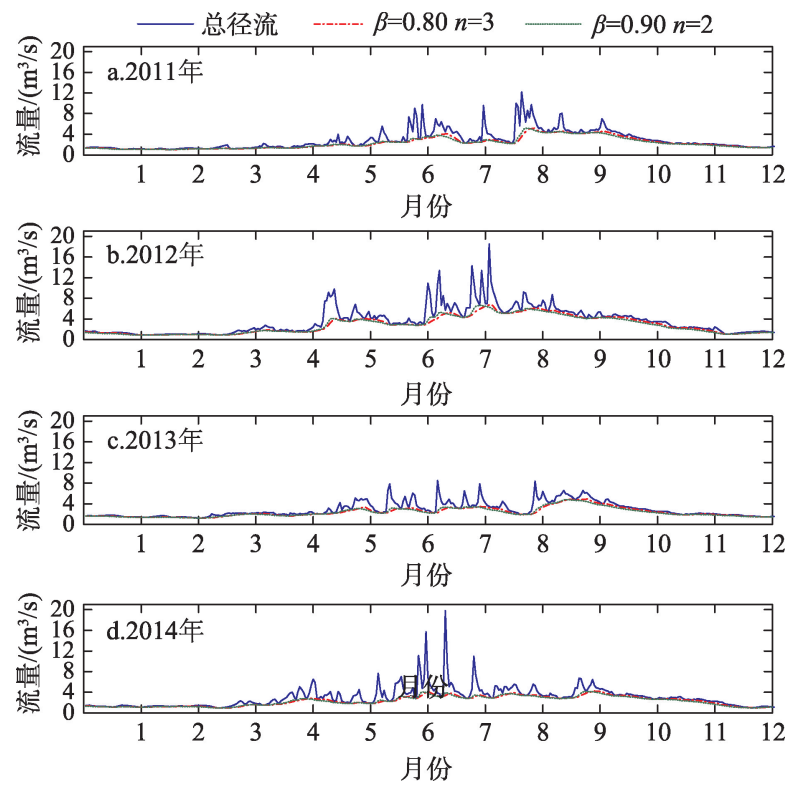

图 4 数字滤波法不同滤波参数汛期基流分割对比

Fig.4 Results of basaflow separation of different parameter values of digital filtering
种方法分割出的基流曲线非常一致,尤其是水量较 少的 1-3 月及 11-12月,两种方法分割的基流过程线 基本重合; 在丰水期,滑动最小值法分割的基流过 程线基本处于数字滤波法分割过程线的下方。典 型年两种方法分割基流的相关性系数分别为 $0.9079 、 0.9724 、 0.9488 、 0.9387$ (图 6)。可见当数字滤 波法中 $\beta$ 取 0.80 , 经过 3 次滤波分割的基流结果与 滑动最小值法的分割结果非常接近。

\section{4 基流的年际变化趋势}

采用数字滤波法对研究区 1980-2014年的基流 进行分割,所得年径流、基流及 $B F I$ 的变化过程线及 趋势线如图 7 所示。在研究期内, 年径流、基流及 $B F I$ 均呈增长趋势, 增幅分别为 $0.086\left(\mathrm{~m}^{3} / \mathrm{s}\right) / 10 \mathrm{a}$ 、 $0.169\left(\mathrm{~m}^{3} / \mathrm{s}\right) / 10 \mathrm{a} 、 0.038 / 10 \mathrm{a}$, 其中基流的增长趋势大 于年径流。1989年年径流和基流均最大, 分别为 4.84 和 $3.18 \mathrm{~m}^{3} / \mathrm{s}$, 为丰水年, 该年的 $B F I$ 为 0.66 ;
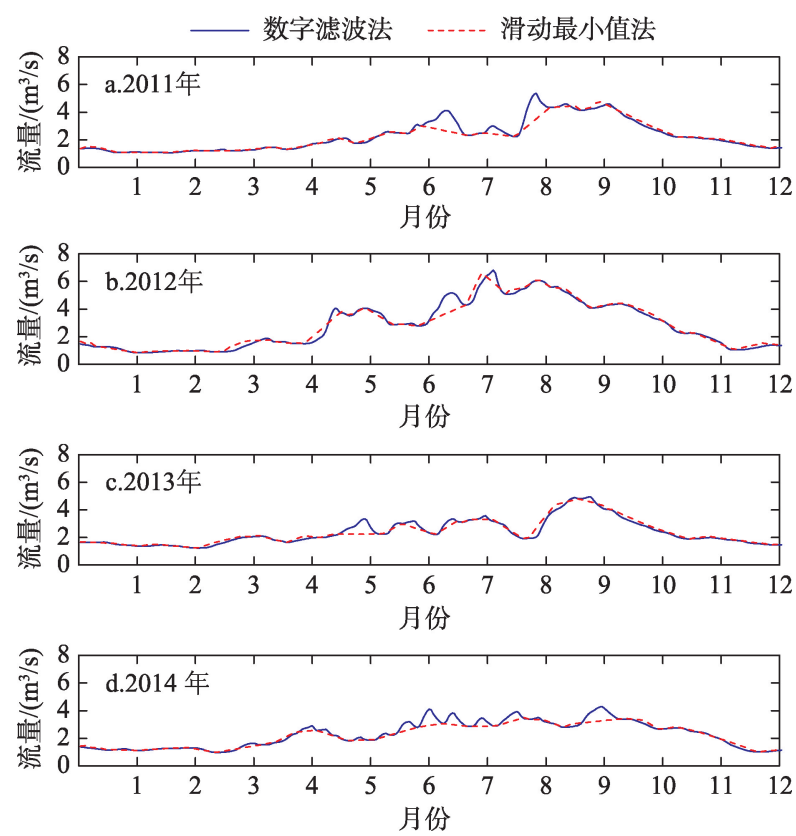

图 5 两种方法基流分割结果对比

Fig.5 Comparison of baseflow separation between digital filtering and smoothed minima 

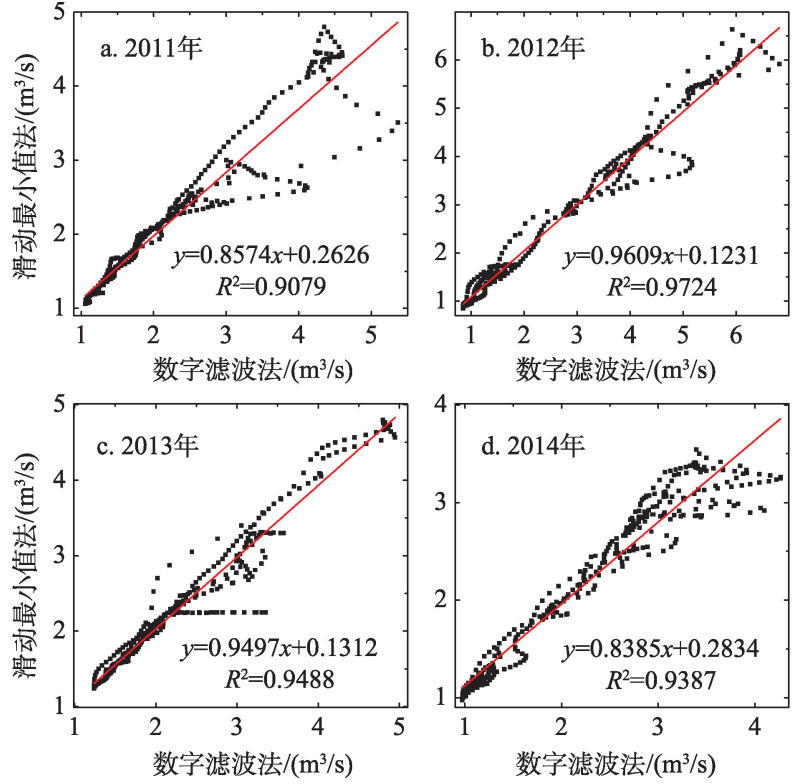

图 6 两种基流分割方法结果的相关性分析

Fig.6 Correlation analysis between results of the two automatic baseflow separation methods

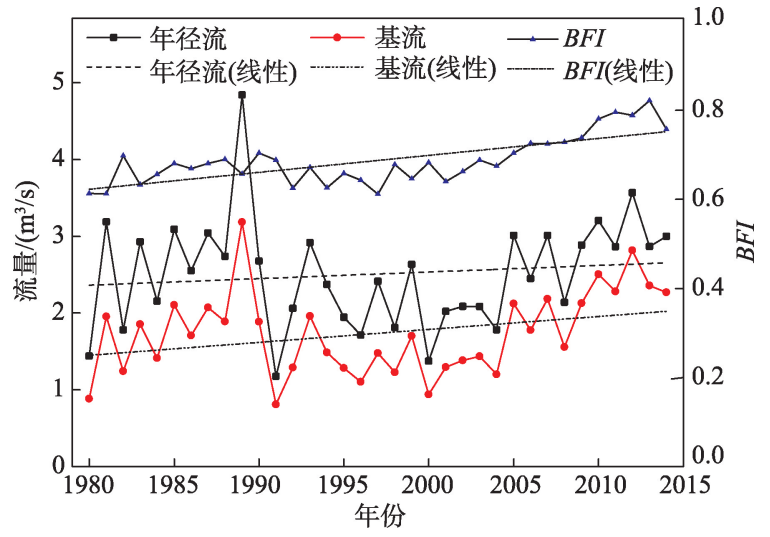

图 7 药水河流域年径流、基流及 BFI的变化过程

Fig.7 Change of annual runoff, baseflow, and BFI of the Yaoshui Basin

1991 年为枯水年, 年径流和基流均最小, 分别为 1.17 和 $0.81 \mathrm{~m}^{3} / \mathrm{s}$, 对应的 $B F I$ 为 0.69 。丰水年降水 量相对较大, 产生较多的地表径流, 枯水年河川径 流量主要来自于基流,因此丰水年的基流指数 $B F I$ 小于枯水年。通过 $\mathrm{M}-\mathrm{K}$ 趋势检验, 研究期内年径 流、基流和 $B F I$ 的 $Z$ 值分别为 $0.91 、 2.13 、 4.22$, 说明 3 个系列都呈增长趋势, 其中 $B F I$ 增长趋势最为显著, 通过了 $1 \%$ 的显著性检验, 基流通过了 $2.5 \%$ 的显著 性检验, 增长较为显著; 年径流未通过 $10 \%$ 的显著 性检验, 增长趋势不明显。

有研究显示, 青海省近 50 年来降水量呈增加趋 势(杨东等, 2013), 其变化过程线与图 7 所示的年径
流和基流的变化过程线相似,可见年径流和基流与 降水之间存在着密切关系。同时, 由于近年来对水 土保持的重视,在流域内采取了大规模的植树造林 等水土保持措施,故研究区近 1991-2013 年植被覆 盖度呈明显上升趋势(陈首涁等, 2013)。土地利用 方式的改变导致降水过程中雨水滞留时间变长, 下 渗水量增加,造成地下水补给量增加,引发基流量 增大。因此,在研究区年径流增加趋势不显著的情 况下,基流指数 $B F I$ 增长趋势明显。

\section{4 讨论}

\section{1 基流分割结果的合理性分析}

结合数字滤波法及滑动最小值法, 分割得到药 水河流域 1980-2014 年的平均基流指数 BFI 为 0.69 。一个地区的 $B F I$ 与下垫面土壤类型和植被覆 盖等密切相关。药水河流域土壤为壤土,下垫面透 水性良好。地下水多为孔隙含水层, 储水能力较 好。流域内大量分布着牧草、灌木丛、林地, 部分地 区植被度达 0.8 以上。由此可见,流域下垫面有利 于降水下渗,补给基流。因此,药水河流域基流指 数 $B F I$ 较大。此外,已有的基流分割研究成果显示, 同为黄河上游地区的玛曲一唐乃亥及唐乃亥一循 化区间的 BFI 分别为 0.70 和 0.79 (陈利群, 刘昌明, 郝芳华等, 2006; 林学钰等, 2009), 进一步证明了本 文结合使用滑动最小值法和数字滤波法进行基流 分割结果的合理性。研究区的高 BFI说明该流域的 基流量对河川径流量的贡献较大, 同时也说明黄河 上游干旱半干旱地区的基流是区域水资源中的重 要组成部分。

\section{2 数字滤波法在实际应用中的问题}

数字滤波法在自动基流分割方法中的应用最 为广泛。很多学者在应用数字滤波法研究基流时, 常根据已有研究成果来确定参数值 $\beta$ 和滤波次 数。这种做法存在一定的局限性。根据 Smakhtin (2001) 的研究, 海拔大于 $1100 \mathrm{~m}$ 的干旱半干旱地 区, $\beta$ 的取值应比 0.925 小 $2 \%$ 左右。而本文得出 $\beta$ 取 0.80 时,经过 “正一反一正” 3 次滤波可得到较好 的结果。由此可见,数字滤波法中的 $\beta$ 值及滤波次 数需结合流域特征来确定。

不同流域的 $B F I$ 值存在很大差异。根据中国一 级区多年平均年水资源量统计(水利部水利水电规 划设计总院, 2014), 全国平均 $B F I$ 为 0.26 ,西北诸河 区为 0.57 , 黄河区为 0.43 , 本文计算得出的黄河上游 
药水河流域的基流指数为 0.69 。可见不同流域的 BFI 值差异明显, 其与降雨、地形地貌、地质岩性、植 被覆盖、人类活动等因素都有关联, 如果不对研究 区进行综合分析而移植已有研究区参数成果, 或代 人文献推荐的通用参数进行计算,会带来基流分割 结果的不确定性。

\section{3 数字滤波法与滑动最小值法的配合使用}

滑动最小值法是通过连接流量过程线上的一 系列拐点而得到的基流过程, 基本符合基流的特 性,该法简捷易用,但基流分割结果偏小。Eckhardt (2008) 将滑动最小值法与其他方法进行比较, 认为 滑动最小值法得到的基流指数最小; 林凯荣等 (2008)使用滑动最小值法对汉江老灌河流域进行基 流分割,也指出基流分割结果偏小。

数字滤波法是由总流量过程通过三道滤波通 道的层层过滤而获得基流过程,得出的基流曲线较 为平滑, 可反映出基流过程的稳定性和迟滞性。研 究表明, 用数字滤波法获取的基流过程线比较符合 流域降雨一径流过程演变的物理规律, 体现出流域 下垫面对地下净雨的汇流作用, 故该基流分割方法 目前在国际上得到了广泛应用(徐磊否等, 2011)。 但受限于水文勘测技术, 目前基流还不能通过直接 监测取得。由于缺乏实测基流过程, 在使用数字滤 波法对特定流域进行基流分割时, 参数值 $\beta$ 及滤波 次数难以确定。

本文在对研究区进行基流分割时, 充分结合两 种自动基流分割方法的优点。先使用滑动最小值 法对径流过程进行基流分割, 然后令数字滤波法中 的参数分别取不同值, 对研究区作进一步基流分 割, 获得不同滤波参数下的基流指数; 最后参照滑 动最小值法的分割结果, 并综合分析流域特征确定 数字滤波法的 $\beta$ 值及滤波次数, 从而实现研究区基 流的自动分割, 获得合理的基流过程, 并可确保具 有较高的精度。

\section{4 基流指数的区域分异规律}

本文分割得到黄河上游小流域多年平均基流 指数 $B F I$ 为 0.69 。全国其他地区的多年平均基流指 数如图 8 所示。其中, 北方地区年均降水 $328 \mathrm{~mm}$, 总径流量 $4.38 \times 10^{3}$ 亿 $\mathrm{m}^{3}$, 基流量 $1.57 \times 10^{3}$ 亿 $\mathrm{m}^{3}$, $B F I$ 为 0.36 ; 南方地区年均降水 $1214 \mathrm{~mm}$, 总径流量 $2.30 \times 10^{4}$ 亿 $\mathrm{m}^{3}$, 基流量 $5.60 \times 10^{3}$ 亿 $\mathrm{m}^{3}, B F I$ 为 0.24 ; 西北诸河区与黄河区的 $B F I$ 分别为 0.57 和 0.43 。由 于干旱半干旱地区年均降水量小, 总径流量少, 基

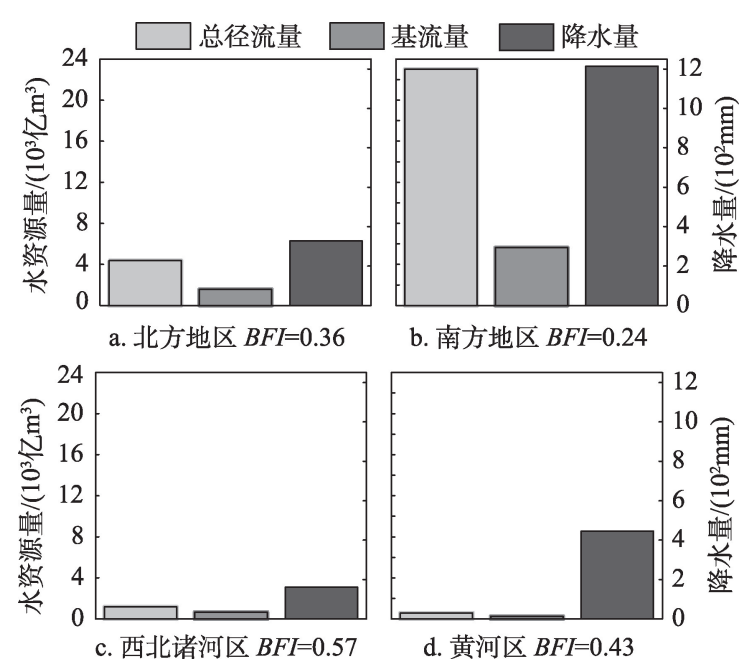

图 8 全国部分地区基流指数对比

Fig.8 Comparison of BFI of northern, southern, and northwestern China and the Yellow River region

流所占比重大, 故 BFI偏大; 南方地区虽年均降水量 大, 总径流量多, 基流所占比重小, 故 $B F I$ 亦小。对 比其他研究成果(豆林等, 2010; 崔玉洁等, 2011; 张 华等, 2011; 王冠等, 2015; 张文娜等, 2015)发现, 如 果具体到典型小流域,无论位于干旱区还是湿润 区, 基流指数都可能有较大值或较小值, 可见 $B F I$ 与 研究区所处的气候区并无绝对关系, 而受降水、地 形地貌、地质岩性、植被覆盖等多种因素的综合影 响。本小节在分析基流指数的区域分异规律时, 仅 对降水进行了讨论,如何区分各因素对不同区域基 流指数分异变化的影响还有待深人分析。

\section{5 结论}

本文选取位于干旱半干旱地区的药水河流域 径流过程为研究对象, 分别使用滑动最小值法和数 字滤波法对典型年进行基流分割, 确定数字滤波法 的参数值, 然后用数字滤波法对 1980-2014 年日均 径流资料进行基流分割,并分析整个资料系列基流 的变化趋势, 主要结论如下:

(1) 数字滤波法和滑动最小值法都可以快速分 割基流, 且可保证一定的精度, 克服了人工操作的 繁琐性和主观性。但滑动最小值法的分割结果偏 小, 数字滤波法的 $\beta$ 值和滤波次数难以确定。因 此, 在实际应用中, 应充分结合两种方法, 确定最优 的基流分割方案。

(2) 研究区 1980-2014 年的平均基流指数为 0.69 , 总体基流指数较高, 高于全国平均值 0.26 、西 
北诸河区的 0.57 及黄河区的 0.43 , 显示黄河上游干 旱半干旱地区的基流对于区域水资源构成和社会 经济发展具有更重要的作用。

(3) 1980-2014年, 研究区年径流、基流、BFI都 呈增长趋势。 $\mathrm{MK}$ 趋势检验结果显示, 年径流未通 过 10\%的显著性检验, 增长趋势不明显; 基流和 $B F I$ 分别通过了 $2.5 \%$ 和 $1 \%$ 的显著性检验, 增长趋势 显著。

\section{参考文献(References)}

陈利群, 刘昌明, 郝芳华, 等. 2006. 黄河源区基流变化及影 响因子分析 [J]. 冰川冻土, 28(2): 141-148. [Chen L Q, Liu C M, Hao F H, et al. 2006. Change of the baseflow and it's impacting factors in the source regions of Yellow River[J]. Journal of Glaciology and Geocryology, 28(2): 141-148.]

陈利群, 刘昌明, 李发东. 2006. 基流研究综述 [J]. 地理科学 进展, 25(1): 1-15. [Chen L Q, Liu C M, Li F D. 2006. Reviews on base flow researches[J]. Progress in Geography, 25(1): 1-15.]

陈首彬, 赫晓慧, 王芳. 2013. 流域植被覆盖度变化对湟水河 含沙量的影响 [J]. 人民长江, 44(19): 78-80. [Chen S B, He X H, Wang F. 2013. Influence of vegetation coverage change on sediment content in Huangshui River Watershed [J]. Yangtze River, 44(19): 78-80.]

崔玉洁, 刘德富, 宋林旭, 等. 2011. 数字滤波法在三峡库区 香溪河流域基流分割中的应用[J]. 水文, 31(6): 18-23. [Cui Y J, Liu D F, Song L X, et al. 2011. Application of digital filtering theory in baseflow separation in Xiangxi River Watershed of three gorges reservoir area[J]. Journal of China Hydrology, 31(6): 18-23.]

董晓华, 邓霞, 薄会娟, 等. 2010. 平滑最小值法与数字滤波 法在流域径流分割中的应用比较 [J]. 三峡大学学报: 自 然科学版, 32(2): 1-4. [Dong X H, Deng X, Bo H J, et al. 2010. A comparison between smoothed minimma and digital filtering methods applied to catchment baseflow separation[J]. Journal of China Three Gorge University: Natural Sciences, 32(2): 1-4.]

豆林, 黄明斌. 2010. 自动基流分割方法在黄土区流域的应 用研究 [J]. 水土保持通报, 30(3): 107-111, 133. [Dou L, Huang M B. 2010. Applied study of baseflow separation methods in watersheds of Loess Plateau[J]. Bulletin of Soil and Water Conservation, 30(3): 107-111, 133.]

黄国如. 2007. 流量过程线的自动分割方法探讨 [J]. 灌溉排 水学报, 26(1): 73-78. [Huang G R. 2007. Base flow separation from daily flow hydrograph using automated techniques[J]. Journal of Irrigation and Drainage, 26(1): 73-78.] 雷泳南, 张晓萍, 张建军, 等. 2011. 自动基流分割法在黄土 高原水蚀风蚀交错区典型流域适用性分析[J]. 中国水土
保持科学, 9(6): 57-64. [Lei Y N, Zhang X P, Zhang J J, et al. 2011. Suitability analysis of automatic baseflow separation methods in typical watersheds of water-wind erosion crisscross region on the Loess Plateau, China[J]. Science of Soil and Water Conservation, 9(6): 57-64.]

雷泳南, 张晓萍, 张建军, 等. 2013. 窟野河流域河川基流量 变化趋势及其驱动因素 [J]. 生态学报, 33(5): 1559-1568.

[Lei Y N, Zhang X P, Zhang J J, et al. 2013. Change trends and driving factors of base flow in Kuye River Catchment [J]. Acta Ecologica Sinica, 33(5): 1559-1568.]

林凯荣, 陈晓宏, 江涛, 等. 2008. 数字滤波进行基流分割的 应用研究 [J]. 水力发电, 34(6): 28-30, 88. [Lin K R, Chen $\mathrm{X} \mathrm{H}$, Jiang T, et al. 2008. Application and study on base flow separation using digital filters[J]. Water Power, 34(6): 28-30, 88.]

林学钜, 廖资生, 钱云平, 等. 2009. 基流分割法在黄河流域 地下水研究中的应用 [J]. 吉林大学学报: 地球科学版, 39 (6): 959-967. [Lin X Y, Liao Z S, Qian Y P, et al. 2009. Baseflow separation for groundwater study in the Yellow River Basin, China[J]. Journal of Jilin University: Earth Science Edition, 39(6): 959-967.]

莴孝芳, 刘方贵, 邢贞相. 2007. 水文学的发展及其所面临的 若干前沿科学问题 [J]. 水利水电科技进展, 27(1): 75-79. [Rui X F, Liu F G, Xing Z X. 2007. Advances in hydrology and some frontier problems[J]. Advances in Science and Technology of Water Resources, 27(1): 75-79.]

水利部水利水电规划设计总院. 2014. 中国水资源及其开发 利用调查评价 $[\mathrm{M}]$. 北京: 中国水利水电出版社. [Ministry of Water Resources, China Renewable Energy Engineering Institute. 2014. Zhongguo shuiziyuan jiqi kaifa liyong diaocha pingjia[M]. Beijing, China: China Waterpower Press.]

王冠, 鲁程鹏, 李姝蕾, 等. 2015. 五种基流分割方法在长江 螺山站的应用对比研究 [J]. 水资源与水工程学报, 26(3): 118-123. [Wang G, Lu C P, Li S L, et al. 2015. Applied comparison of five separation methods of base flow at Luoshan Station of Yangtze River[J]. Journal of Water Resources and Water Engineering, 26(3): 118-123.]

王雁林, 王文科, 钱云平, 等. 2008. 黄河河川基流量演化规 律及其驱动因子探讨 $[\mathrm{J}]$. 自然资源学报, 23(3): 479-486. [Wang Y L, Wang W K, Qian Y P, et al. 2008. Change characteristics and driving forces of base flow of Yellow River Basin[J]. Journal of Natural Resources, 23(3): 479-486.]

徐否否, 刘敬林, 金昌杰, 等. 2011. 水文过程的基流分割方 法研究进展 [J]. 应用生态学报, 22(11): 3073-3080. [Xu L L, Liu J L, Jin C J, et al. 2011. Baseflow separation methods in hydrological process research: A review[J]. Chinese Journal of Applied Ecology, 22(11): 3073-3080.]

杨东, 王慧, 程军奇, 等. 2013. 近 50 年青海省气候变化特征 及其与 ENSO 的关系 [J]. 生态环境学报, 22(4): 547-553. [Yang D, Wang H, Cheng J Q, et al. 2013. Climate change in 
Qinghai and its relationship with ENSO in the recent 50 years[J]. Ecology and Environmental Sciences, 22(4): 547-553.] 张华, 张勃, 赵传燕. 2011. 黑河上游多年基流变化及其原因 分析 [J]. 地理研究, 30(8): 1421-1430. [Zhang H, Zhang B, Zhao C Y. 2011. Annual base flow change and its causes in the upper reaches of Heihe River[J]. Geographical Research, 30(8): 1421-1430.]

张文娜, 刘志辉, 王荣军, 等. 2015. 数字滤波法在天山北坡 军塘湖河流域流量基流分割中的应用 $[\mathrm{J}]$. 干旱区研究, 32(1): 35-39. [Zhang W N, Liu Z H, Wang R J, et al. 2015. Application of digital filtering theory in baseflow separation of Juntanghu River Watershed in northern slope of the Tianshan Mountains[J]. Arid Zone Research, 32(1): 35-39.]

Aksoy H, Kurt I, Eris E. 2009. Filtered smoothed minima baseflow separation method[J]. Journal of Hydrology, 372(14): 94-101.

Arnold J G, Allen P M, Muttiah R, et al. 1995. Automated base flow separation and recession analysis techniques[J]. Ground Water, 33(6): 1010-1018.

Eckhardt K. 2008. A comparison of baseflow indices, which were calculated with seven different baseflow separation methods[J]. Journal of Hydrology, 352(1-2): 168-173.

Nathan R J, McMahon T A. 1990. Evaluation of automated techniques for base flow and recession analyses[J]. Water Resources Research, 26(7): 1465-1473.

Rutledge A T. 1998. Computer programs for describing the recession of ground-water discharge and for estimating mean ground-water recharge and discharge from streamflow records-update[R]. U. S. Geological Survey Water-Resources Investigations Report 98-4148.

Sloto R A, Crouse M Y. 1996. HYSEP: A computer program for streamflow hydrograph separation and analysis[R]. U. S. Geological Survey, Water-Resources Investigations Report 96-4040.

Smakhtin V U. 2001. Estimating continuous monthly baseflow time series and their possible applications in the context of the ecological reserve[J]. Water S A, 27(2): 213-218.

Wahl K L, Wahl T L. 1995. Determining the flow of Comal Springs at New Braunfels, Texas[Z]. Texas Water'95. San Antonio, TX: American Society of Civil Engineers.

\title{
Comparative study on two automatic baseflow separation methods in the arid and semi-arid regions
}

\author{
LI Rui ${ }^{1,2,3}$, ZHANG Shifeng $^{1,2^{*}}$ \\ (1. Institute of Geographic Science and Natural Resources Research, CAS, Beijing 100101, China; \\ 2. Key Laboratory of Water Cycle and Related Land Surface Processes, CAS, Beijing 100101, China; \\ 3. University of Chinese Academy of Sciences, Beijing 100049, China)
}

\begin{abstract}
Baseflow is a crucial component of streamflow. In the arid and semi-arid region, baseflow plays an important role in maintaining the stability and sustainability of the river flow and determining the ecological water requirement. Therefore, the results of baseflow separation are of great importance. In our research, a typical drainage basin located in the upstream of the Yellow River region was taken as the study area. Considering runoff in several typical years, we used smoothed minima and determined the parameters of digital filtering. Then we used digital filtering for baseflow separation using the data from 1980-2014 and analyzed the trend of baseflow. The results show that digital filtering performed better in the arid and semi-arid region and the results gained from smoothed minima indicate lower baseflow values. In areas where the parameters are difficult to determine, baseflow estimation should take advantage of both methods. The average BFI of the study area from 1980 to 2014 was 0.69 , which was greater than the national average (0.26), BFI of the rivers in northwestern China (0.57), and BFI of the Yellow River region (0.43). Trend analysis shows that the increase of annual flow, baseflow, and BFI was $0.086\left(\mathrm{~m}^{3} / \mathrm{s}\right) / 10 \mathrm{a}, 0.169\left(\mathrm{~m}^{3} / \mathrm{s}\right) / 10 \mathrm{a}$, and $0.038 / 10 \mathrm{a}$. MK trend test results show that the growth of annual flow was not obvious because it did not pass the significance test of $90 \%$; baseflow and BFI showed significant positive trends for they had passed the significance test of $97.5 \%$ and $99 \%$ respectively.
\end{abstract}

Key words: arid and semi-arid regions; automatic baseflow separation; smoothed minima; digital filtering; baseflow index 